\title{
Development of a Cloud-based Network Teaching Platform
}

\author{
https://doi.org/10.3991/ijet.v13i04.8258 \\ Renshu Huang \\ Xiamen Institute of Software Technology, Xiamen, China \\ 2123065184 @qq. com
}

\begin{abstract}
At present, teachers and students are unable to communicate with each other directly in the network courses so that the teaching quality has been compromised. Moreover, teaching process becomes slow in traditional teaching mode of network course. In this project, we introduced an innovative PBL (Problem Based Learning) teaching method and combined teacher and student interaction for a network course, while utilizing cloud computing. In addition, all workstations were card workstations to reduce the delay of teaching task. We designed a platform with a personnel information module and a learning service module. The learning service module covers three main functions: teaching service resources management, online coaching, and assignment submission and correction. The evaluation outcome shows that the learning outcome and learning interest was superior for students who used the PBL network teaching platform, compared to the students who didn't use this platform.
\end{abstract}

Keywords-Cloud computing, network course, network security

\section{$1 \quad$ Introduction}

In 2006 Cloud computing was first put forward by Google, a globally famous search service provider [1]. The popularization of the concept of cloud computing is more conducive to the development of network course teaching which mainly relies on Internet [2]. The computing platform is provided by the cloud computing not only for the large-scale computational schemes but also for mobile devices, such as mobile phones, tablet computers and notebook computers. This can achieve relevant data communication by this large-scale computing platform. The platform is connected with countless computers through Internet and can obtain relevant calculating function and other services that they need depending.

Due to the technical advantages cloud computing has been used widely used for teaching and is known as Cloud Computing Assisted Instruction [3]. The application of the cloud computing network teaching platform can make full use of the specialty of cloud computing to create a course environment for students' classroom learning and in accord with their learning features. Cloud computing has many functions, such as memory, computing and software which can provide rich support for the construction of network course platform. At present, some corresponding teaching assistant 
software has been gathered on the cloud computing platform including the online learning system, instructional management system, network teaching resource library, school-parents interactive platform and campus website with few functions. These are: creating a teaching environment, designing teaching resources, organizing teaching activities, and implementing teaching evaluation [4]. We can give full play to the characteristics of cloud computing platform and implement the learning characteristics for students, only by combining these functions. We can make full use of the specialty of cloud computing platform only by integrating these functions to implement the functions for students according to their learning features. Thus, parents, students and teachers can be connected with each other through using this new-type network teaching platform.

\section{State of the art}

The course feature of the majors related to computer is that the information resources of all courses are rich. Moreover, a large amount of computer practice is needed in the network course learning of computer specialty, which has high requirements for both hardware and software network course teaching system of all computer specialties. Besides, the emergence of a large number of mobile devices provide the practice basis for computer courses, so that we can implement the corresponding network teaching.

Google Inc. which is located in America was a pioneer of combining cloud computing and network course teaching for the application of cloud computing in the network teaching. Google Inc has six modules for application of cloud computing in the network course teaching. These are: Google Sites, G-mail, Google Assistance Platform, Google Talk, Google Doc and Google Calendar [5]. Thomas et al [6] provided insights into the possibility of using cloud computing delivery for originating a new instructional paradigm. This paradigm made a shift possible from the traditional practice of teaching as a private affair to a peer-reviewed transparent process and made it known how student learning can be improved generally, not only in one's own classroom but also beyond it. Murah [7] applied the cloud computing teaching technology to the computer network courses for graduates, created a cooperative learning environment and set the function of free learning. After using the system, most of students' feedback is that the learning effect was better.

At present, the application of cloud computing in the network course teaching of Chinese colleges and universities is still at the primary development stage and many online education companies with different scales have appeared in the whole network course teaching process. Among those, the development scale of Baidu in the network course education is the largest. Baidu is an internet company synthesizing multiple elements. Because of its features, its many original functions can be combined with cloud computing for the corresponding network course teaching. Baidu has developed these modules: Baidu Zhidao, Baidu Chuanke, Baidu Netcard, Baidu Xueshu, etc [8]. These modules can be integrated to test the combination of network course teaching and cloud computing. Baidu Netcard has corresponding network storage function. On 
Baidu Zhidao, students and even all users in internet can ask questions and answer them. On Baidu Chuanke, teachers and students can conduct corresponding online classroom teaching. Baidu Xueshu can provide corresponding learning resources and academic resources for students, so as to improve their overall academic attainments.

At present, the application of domestic network course teaching can help students to learn corresponding courses very conveniently in front of the electronic equipment. It can also help them to break through the constraints of time and geographical location, so that students are able to learn the knowledge they want at any moment. However, the shortcoming of this type of network course is that teachers and students are unable to communicate with each other face to face directly which results in that teachers and students cannot evaluate the teaching quality in real time. In addition, teachers cannot adjust the teaching content correspondingly. If the teaching content cannot be adjusted correspondingly, the quality of the network course teaching will be lowered greatly. Moreover, the mode of the traditional non-linear editing teaching network is that "a card workstation drives several non-card workstations" [9]. Actually, to upload and download videos and audios is very important in the Radio and TV industry, enterprises and public institutions, and other programming institutions. Therefore, it cannot be neglected in teaching. However, in the actual teaching process, many students need practice but the traditional non-linear editing teaching network mode will result in that the demand pressure to all students for uploading and downloading is centralized on a few of card workstations and the teaching task is delayed due to queuing up and waiting.

Based on the problems mentioned above, we applied the innovative PBL teaching method to plan teaching methods in whole class so that students can be problemoriented and learn the corresponding courses. Moreover, in this research, we applied the teachers-students feedback technology, and all workstations were card workstations, so that every student could practice the complete TV programming process independently. We hope it can provide new trains of thought and reference for the computer network courses.

\section{Theoretical construction}

In this research, we built the theoretical basis of the design of the multimedia experiment teaching platform for the course, Network Security, based on the cloud computing put forward in this paper from two aspects: the PBL teaching method and cloud computing.

\subsection{The PBL teaching method}

The purpose of PBL method is to guide students to explore corresponding study by the teaching mode of "solving problems" [10]. Its main feature is that the students can explore the final answers of problems together in groups or by cooperating with others by this method. Moreover, students' autonomous learning ability, innovation con- 
sciousness and innovation ability can be improved effectively by this method. The teaching process frame is shown in Fig.1.

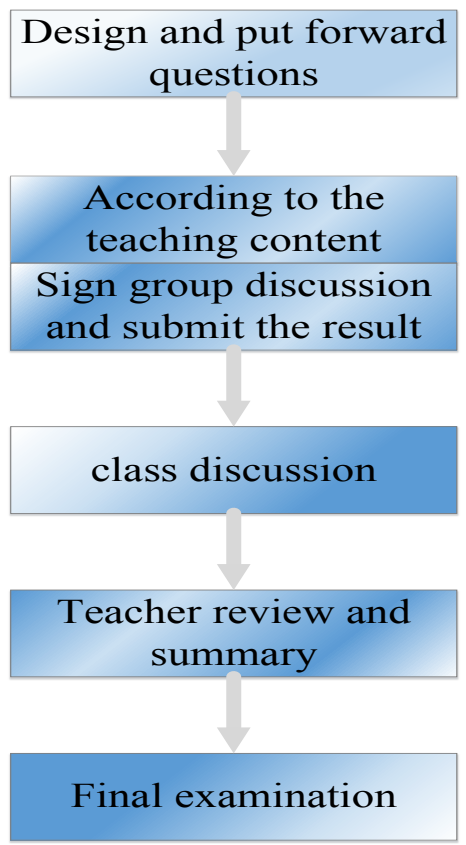

Fig. 1. The PBL teaching process

As shown in Fig.1, in the whole PBL teaching mode, students play the dominant roles, while teachers are the guides in the whole teaching process. Compared with the traditional teaching modes, the PBL teaching mode changes the status of teachers, the roles of students and some other aspects. In the traditional teaching modes, teachers play the dominant roles in the whole teaching process, and teachers only teach their students the content of courses. However, in the PBL teaching mode, the roles of teachers are changed into guides. In this role, teachers not only guide students to initiatively explore the answers of questions, but also play some relevant roles such as discipline experts and task consultants.

\subsection{The theoretical basis of cloud computing}

The cloud computing depends on the numerous personal and enterprise computer terminals, which are connected with Internet. Considering such connection mode, cloud computing has the features of networking and integration, and its theoretical basis is mainly divided into two parts: software-as-a-service and Web MVC framework technology. 


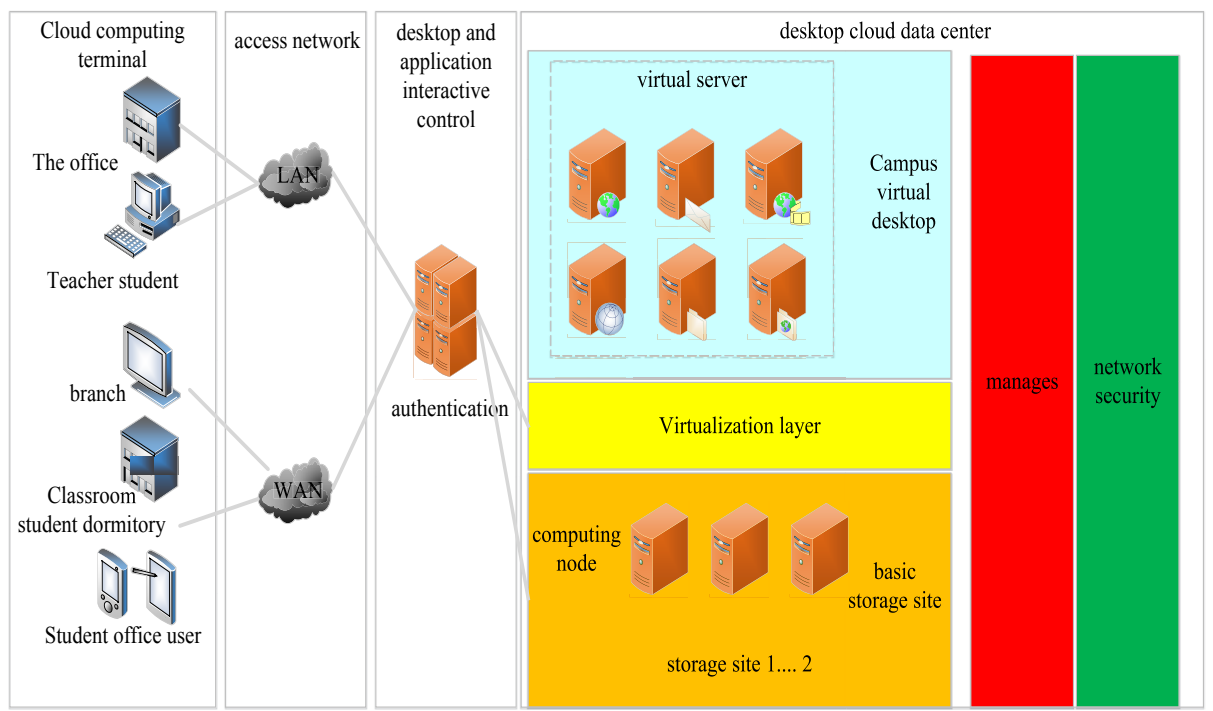

Fig. 2. The frame diagram of cloud computing

Software-as-a-service. Software-as-a-service is an overall service mode with software as center for the development requirements of whole cloud computing service. The operational mode of software-as-a-service has following characteristics:

Connectivity. The feature of software-as-a-service is, that the service suppliers and service users shall be connected correspondingly by internet, so that the software service suppliers can reform the software service conveniently at a distant terminal according to the corresponding requirements put forward by users.

Multi-user. The one-to-many service can be realized by the features of internet. Therefore, the software-as-a-service suppliers can make a software system provide services for many users effectively who hire the software service. Moreover, the software service suppliers can reform software differently according to the requirements of different users.

Service. It is one of the characteristics of software-as-a-service is, Software suppliers can provide corresponding software services according to users' needs. So the key element of software-as-a-service is not the software itself, but the value-added services related to software that meet the individual needs of users.

Web MVC framework technology. At present, Web MVC framework technology is a general large-scale software service framework technology in the world, which mainly covers three layers: view layer, control layer and general layer. Each layer has its own functions to complete the operation mode of the whole Web together. The general framework of the current Web MVC framework technology is composed of Spring framework and ibatis framework.

For the Spring framework in this research, the inversion of control was adopted. Its principle is shown in Fig. 3 as follows and that is the frame diagram of the inversion of control for Spring. 


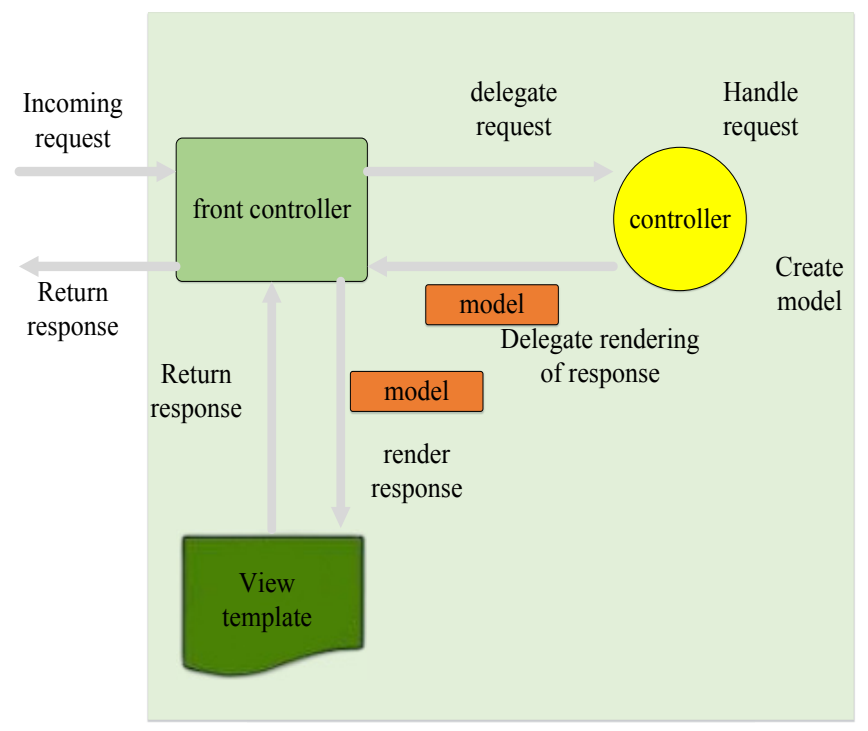

Fig. 3. The frame features of the inversion of control for Spring

As shown in Fig.3, different controller frameworks are generated according to different objects, and the control program is injected into the corresponding application program. After a user submits the corresponding operation request, the controller generated by the Spring framework at the server-side will search the relevant content controlled by Handler Mapping, and then feedback the result searched to the processing center of the controller as the object of Model View, and finally display the corresponding processing result to the user. The transmission process can be expressed with Formula (1) provided below:

$$
P_{r}=P_{i} \frac{G_{i} G_{r} \lambda^{2}}{(4 \pi R)^{2}}=P_{i} \frac{A_{c i} A_{c r}}{R^{2} \lambda^{2}}
$$

Teachers-students feedback technology for network teaching effect. This technology was developed by China Shanghai Jingdi Intelligent Technology Co., Ltd., which paid attention to the function applicability and usability in the design. Through this technology the whole programming process can be realized on every student computer including collecting, editing, making, storing and management, so that students can understand the process of making video and audio completely by teaching and practicing. At the same time it protects the schools' hardware equipments. In this technology, the company adopted ME500e and ME100 Dayang non-linear editing system for the teacher computers and student computers respectively to achieve the collection of SD and HD audio signals, SD and HD mixed edition, stunt, the playing of subtitles and audios, the output of SD and HD video files in various formats, to meet the network teaching needs for making the current SD videos and the future HD videos. The materials can be stored in the center by teacher computers and the as- 
signments can be distributed through the database and the three-party teaching management software. All item files established by teachers and students in editing and producing can be protected safely with passwords. Moreover, the media resources can be searched quickly and managed safely and efficiently based on the resource management of the database. The system provides a uniform ftp server and students can upload the assignments to the center storage to be corrected by teachers through editing the FTP tele-transmission module implanted in the software after they finish them. The finished programs can be generated in the network streaming media or recorded in the DVD disks to be convenient for publishing in the campus network and internet in the future. The advantages of this technology are that all workstations are card workstations, and each student can practice the whole process of TV program production independently. Moreover, based on this technology, a teachers-students feedback technology device module for network teaching effect was set specially in this research. The frame diagram of the main technology content is shown in Fig.4.

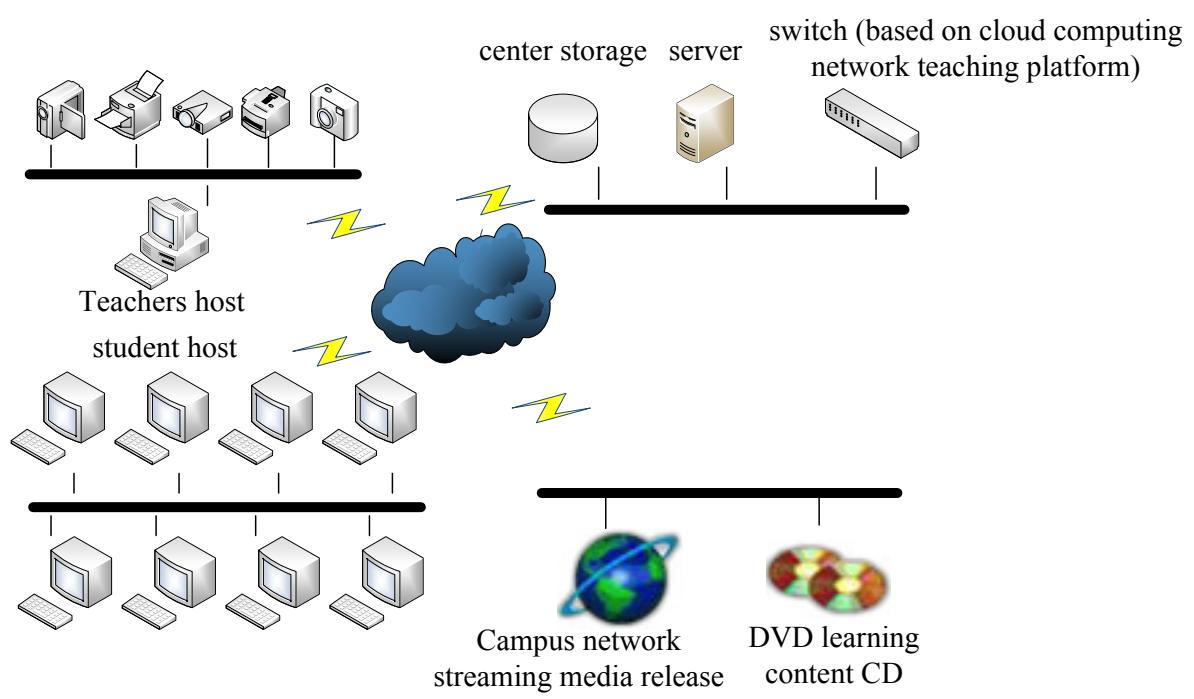

Fig. 4. The frame diagram of the feedback technology for the network teaching platform effect based on cloud computing

\section{Construction of the multimedia experiment teaching platform for the course Network Security based on cloud computing}

\subsection{The frame of the network teaching platform for the course Network Security based on cloud computing}

As a network teaching course, a corresponding platform with perfect functions is needed for the teaching of Network Security. According to the teaching characteristics of the whole network course, the main functions of multimedia experiment teach- 
ing platform constructed for the course is Network Security. It is based on cloud computing that will cover the following two functional modules: the personnel information management module and the learning service module. The specific functional structure chart is shown in Fig.5.

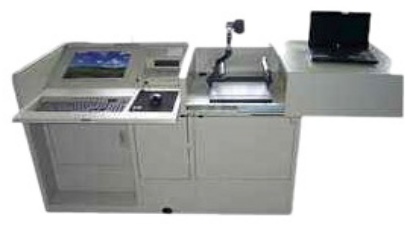

network security course network teaching platform

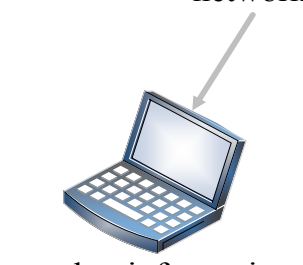

teacher information management module,

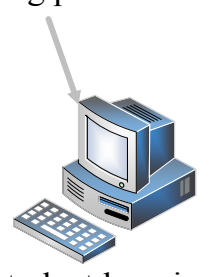

student learning service module

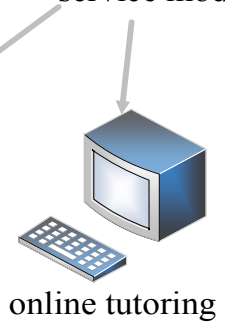

online tutoring

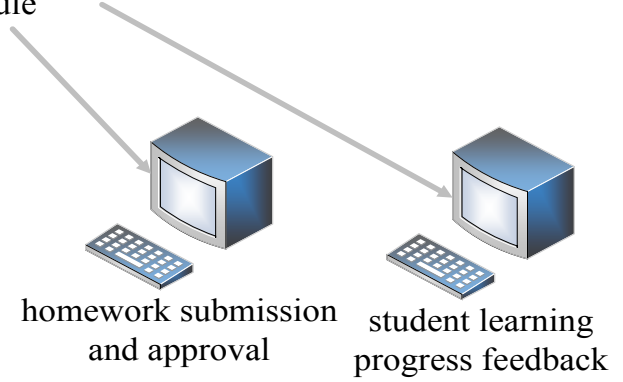
resource management

student learning progress feedback

Fig. 5. The structure chart of the network teaching platform for the course, Network Security, based on cloud computing

\subsection{Design of the network teaching platform for the course Network Security based on cloud computing}

Realize the functions of the personnel information management module. The main function of personnel information management module is to identify the users who $\log$ in the multimedia experiment teaching platform and to distribute their limits of authority.

Realize the functions of the learning service module. The learning service module has three main functions: teaching service resources management, online coaching, assignment submission and correcting. Each function has different tasks. The network teaching platform for the course Network Security based on PBL in this research is shown in Fig.6. 


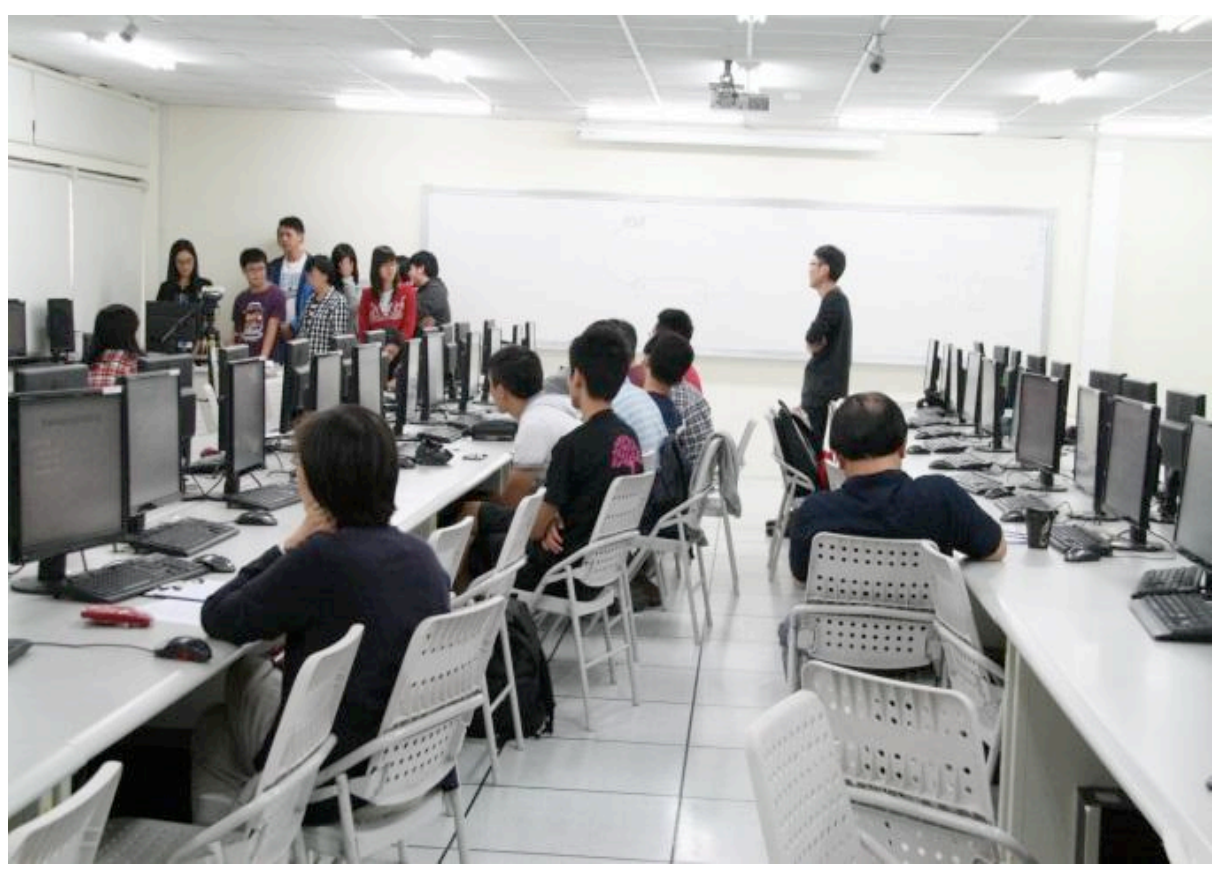

Fig. 6. The network teaching platform for the course Network Security based on PBL

Teaching service resources management. The main purpose of teaching service resources management is to publish the course information of Network Security. This function is connected with G-mail and Google Calendar in the cloud computing platform provided by Google Inc. Moreover, the network resources memory module on the cloud computing platform is docked with this multimedia experiment teaching platform, so as to display the relevant information of the course directly and store the multimedia resources needed by students in class and after class. Furthermore, teachers and students can upload and download relevant information by this functional module.

Online coaching. The function of online coaching covers two parts: teaching in class and answering questions after class. The purpose of this module is to transmit audios and videos by Google Talk on the cloud computing platform. By online coaching, we can determine teachers' teaching state by setting the corresponding permission program, which is also the preparation for the far-reaching promotion of multimedia experiment teaching platform.

Assignment submission and correcting. On this network teaching platform, students can submit their assignments to teachers for correction. Both teachers and students can conduct corresponding operations directly on the cloud terminal through the cloud computing platform. Teachers don't need to download student's assignments for correction, and they can give feedback the results of assignments to students directly by network. 


\subsection{Effect check}

In order to test the overall teaching effect of network course of Network Security based on cloud computing, we selected two parallel classes as the research objects in order to learn Network Security at the same time. The experimental group used the new cloud computing multimedia teaching platform, and the control group accepted the traditional multimedia TTP teaching. Before this course, there was no significant difference in the academic records between the two classes. We analyzed the teaching effect of the multimedia experiment teaching platform combined with the PBL teaching mode through the exam results and course evaluation of the two classes. There were 124 students choosing the course of Network Security including 64 students in the experimental group and 60 students in the control group.

Firstly, we had statistics of the exam results of the students in the two groups after finishing learning the course of Network Security. The concrete content is shown in Table 1.

Table 1. The final exam marking table $(\overline{\mathrm{X}} \pm \mathrm{S})$

\begin{tabular}{|l|c|c|c|c|}
\hline \multicolumn{1}{|c|}{ Item } & Comprehension test & Memory test & Logic test & Total scores \\
\hline Experimental group $(\mathrm{n}=64)$ & $85.89 \pm 6.3$ & $81.54 \pm 3.57$ & $82.57 \pm 3.52$ & $83.5 \pm 10.33$ \\
\hline Control group $(\mathrm{n}=60)$ & $80.1 \pm 10.32$ & $79.79 \pm 5.34$ & $78.96 \pm 5.53$ & $78.3 \pm 19.1$ \\
\hline $\mathrm{t}$ & 6.398 & 2.252 & 4.234 & 6.155 \\
\hline $\mathrm{P}$ & 0.061 & 0.023 & 0.031 & 0.056 \\
\hline
\end{tabular}

The results shows that the academic records of the students using the multimedia experiment teaching platform combined with the PBL teaching mode are better than that of the students who didn't use the platform, especially in the comprehension questions and logic questions. Therefore, the network course based on cloud computing put forward in this paper has a good teaching effect.

Afterwards, we had statistics of the feeling or reactions of the students of the two groups in learning the course of Network Security. The results show that the general evaluation of the students in the experimental group on the teachers' teaching effect is better than that of the students who didn't use the system.

\section{Conclusions}

In this paper we used the innovative PBL teaching method combined with the teachers-students feedback technology for network teaching while utilizing the cloud computing. Besides, all workstations were card workstations in order to reduce the slow pace of teaching process. We built a platform with a personnel information module and a learning service module, where learning service module has three main functions: teaching service resources management, online coaching and assignment submission and correcting. After testing the effect of multimedia experiment teaching platform, it is observed that the network course platform based on cloud computing 
proposed in this paper can improve students' learning effect. To sum up, besides improving the teaching effect, the teaching platform proposed in this paper is able to adapt different teaching modules. In the future, this platform will have a broader development space givn the development of Internet.

\section{References}

[1] Armbrust, M., Fox, A., Griffith, R., et al. Above the clouds: a Berkeley view of cloud computing. Eecs Department, University of California Berkeley, 2009, vol. 53(4), pp. 5058.

[2] Buyya, R., Yeo, C.S., Venugopal, S., et al. Cloud computing and emerging it platforms: vision, hype, and reality for delivering computing as the 5th utility. Future Generation Computer Systems, 2009, vol. 25(6), pp. 599-616. https://doi.org/10.1016/j.future. 2008.12.001

[3] Wang, T.T. The research on the cloud computing assisted instruction under the low carbon circumstance. Advanced Materials Research, 2014, vol. 926-930(926-930), pp. 4677-4680. https://doi.org/10.4028/www.scientific.net/AMR.926-930.4677

[4] Anna, D., Theodoros, M., Ioannis, A., et al. An insight on e-learning and cloud computing systems. Informatica Economica Journal, 2014, vol. 18(4), pp. 14-25.

[5] Kim, S., \& Yoon, A. Do i trust google? An exploration of how people form trust in cloud computing. Proceedings of the American Society for Information Science \& Technology, 2012, vol. 49(1), pp. 1-3. https://doi.org/10.1002/meet.14504901267

[6] Thomas, P.Y. Cloud computing: a potential paradigm for practicing the scholarship of teaching and learning. Electronic Library, 2011, vol. 29(2), pp. 214-224. https://doi.org/10.1108/02640471111125177

[7] Murah, M.Z. Teaching and Learning Cloud Computing. Procedia - Social and Behavioral Sciences, 2012, vol. 59(1), pp. 157-163. https://doi.org/10.1016/j.sbspro.2012.09.260

[8] Hu, H., Zheng, J. Application of Teaching Quality Assessment Based on Parallel Genetic Support Vector Algorithm in the Cloud Computing Teaching System. International Journal of Emerging Technologies in Learning, 2016, vol. 11(8), pp. 16-21.

[9] Liu, F.Q., Lin, Z.Y, Wu, L.L., et al. Design of intelligent question-answering system of network course. Journal of Guizhou Normal University, 2009, vol. 129(2), pp. 282-286.

[10] Ajai, J.T., Imoko, B.I. Gender Differences in Mathematics Achievement and Retention Scores: A Case of Problem-Based Learning Method. International Journal of Research in Education \& Science, 2015, vol. 1(1), pp. 45.

\section{$7 \quad$ Author}

Renshu Huang is a Senior Engineer in Xiamen Institute of Software Technology, Xiamen 361024, China (2123065184@qq.com).

Article submitted 19 August 2017. Published as resubmitted by the author 20 January 2018. 